\title{
Escritos e testemunhos na cultura acadêmica de um curso de Matemática
}

\author{
Writings and testimonies in the academic culture of a Mathematics course
}

\author{
Shirley Patrícia Nogueira de Castro e Almeida ${ }^{1}$ \\ Maria Laura Magalhães Gomes ${ }^{2}$
}

\begin{abstract}
Resumo
Este artigo busca caracterizar a cultura acadêmica do curso de Matemática da Fundação Norte Mineira de Ensino Superior (FUNM), posteriormente Universidade Estadual de Montes Claros (Unimontes), no período 1960-1990. Com a análise de planos de ensino, diários de classe, livros-texto e entrevistas de antigos professores e alunos conduzidas na metodologia da História Oral, o estudo visou compreender as práticas pedagógicas realizadas e as concepções sobre o tipo de professor de Matemática que se pretendia formar. Quanto às práticas, destacaram-se a utilização da exposição oral, a organização do contexto da aula, a explicitação dos objetivos de ensino e o uso de exemplos e de exercícios. O professor formado deveria ser um bom transmissor e conhecedor da matéria, saber articular os conceitos trabalhados à vida cotidiana e a teoria à prática e localizar os conhecimentos histórica e socialmente.
\end{abstract}

Palavras-chave: Cultura Acadêmica; Formação de Professores de Matemática; História Oral; Curso de Matemática da Universidade Estadual de Montes Claros (Unimontes).

\begin{abstract}
This article aims to characterize the academic culture of the Mathematics course offered by Fundação Norte Mineira de Ensino Superior (FUNM), later Universidade Estadual de Montes Claros (Unimontes) in the period 1960-1990. The purpose of this study was to understand the pedagogical practices carried out and the conceptions about the type of mathematics teacher which that course intended to prepare. The sources were academic documents, textbooks and interviews of former teachers and students conducted in the methodology of Oral History. As for the practices, the use of oral exposition, the organization of the classroom context, the explanation of teaching objectives and the use of examples and exercises were highlighted. The prospective teacher should transmit and know well mathematical content, as well as should know how to articulate the concepts to everyday life and theory to practice. In the same way, he or she should be able to locate mathematical knowledge in history and sociology.
\end{abstract}

Keywords: Academic Culture; Teacher Training in Mathematics; Oral History; Course of Mathematics of Universidade Estadual de Montes Claros (Unimontes).

Submetido em: 12/12/2018 - Aceito em: 29/03/2019 - Publicado em: 30/03/2019

${ }^{1}$ Doutora em Educação pela Universidade Federal de Minas Gerais. Professora do Departamento de Métodos e Técnicas Educacionais e do Programa de Pós-graduação em Educação da Universidade Estadual de Montes Claros, Brasil. Email: shirley.castroalmeida@yahoo.com.br

2 Doutora em Educação pela Universidade Estadual de Campinas. Bolsista de Produtividade do CNPq. Professora do Departamento de Matemática e do Programa de Pós-Graduação em Educação da Universidade Federal de Minas Gerais, Brasil. Email: mlauramgomes@gmail.com. 


\section{Cultura escolar, cultura acadêmica e a formação de professores de Matemática em um curso específico}

Os saberes e fazeres mobilizados para a formação de professores de Matemática no curso oferecido em Minas Gerais, pela instituição consolidada posteriormente como Universidade Estadual de Montes Claros, no período de 1960 a 1990, podem ser compreendidos, em grande parte, a partir da análise de componentes da cultura acadêmica, aqui entendida como extensão da cultura escolar, quais sejam: ações pedagógicas, métodos de ensino, formas de avaliação e materiais didáticos utilizados pelos professores formadores de professores. Documentos fundamentais para a compreensão de tais componentes são planos de curso, diários de classe, livros didáticos e as narrativas de nossos colaboradores ${ }^{3}$ em uma pesquisa na qual usamos a metodologia da História $\mathrm{Oral}^{4}$.

Cabe aqui registrar, em nossa concepção, a diferença entre "escritos" e "testemunhos", esclarecendo que os primeiros dizem respeito às fontes escritas, anteriormente citadas, mobilizadas na análise. Já os "testemunhos" referem-se às narrativas das memórias de nossos colaboradores acerca de seus fazeres e saberes durante sua formação acadêmica e/ou atuação como docentes. Neste artigo, fazemos dialogar narrativas e documentos escritos para compreender o que se ensinava e aprendia no curso em foco e registramos resultados de nossas análises sobre o tipo de professor de Matemática que se queria formar.

Conforme Sarlo (2006) em entrevista a Mota (2006), ao operar com memórias é importante empreender "uma reconstrução que trabalhe com todas as fontes possíveis: não só testemunhos, mas também as fontes escritas, que são indispensáveis para a compreensão do movimento das idéias (sic)". Destarte, esse foi o movimento que fizemos no intuito de construir nossa análise da cultura escolar do curso de Matemática estudado.

Dominique Julia (2001, p. 10) conceitua cultura escolar como

conjunto de normas que definem conhecimentos a ensinar e condutas a inculcar, e um conjunto de práticas que permitem a transmissão desses conhecimentos e a incorporação desses comportamentos; normas e práticas coordenadas a finalidades que podem variar segundo as épocas (finalidades religiosas, sociopolíticas ou simplesmente de socialização).

Conforme o autor, a cultura escolar nos oferece indícios de que a escola, mais que um espaço de transmissão de conhecimentos, constitui-se em lugar de inculcação de

\footnotetext{
${ }^{3}$ Contamos com as entrevistas dos professores Rosa Terezinha Paixão Durães, Ronaldo Dias Ferreira, Francisco Bastos Gil, Edson Guimarães, Mariza Monteiro Guimarães, Dilma Silveira Mourão, Maria de Lourdes Ribeiro Paixão, Rosina Rabelo Nuzzi Ribeiro, Edson Crisóstomo dos Santos, João Barbosa de Souza e Sebastião Alves de Souza, realizadas em 2012 e 2013. Essas entrevistas foram feitas para a tese de doutorado de Almeida (2015).

${ }^{4}$ Intencionalmente, não realizamos, neste texto, considerações de cunho teórico-metodológico em relação à metodologia da História Oral. O leitor interessado poderá consultar Almeida (2015).
} 
DOI: https://doi.org/10.20396/zet.v27i0.8654227

comportamentos. Faria Filho, Gonçalves, Vidal e Paulilo (2004, p. 144) salientam que "Julia convidava os historiadores da educação a se interrogarem sobre as práticas cotidianas, sobre o funcionamento interno da escola" - convite aceito por nós na busca de compreender como se deu a formação de professores de Matemática no interior da Fundação Norte Mineira de Ensino Superior (FUNM)/Unimontes no período de 1960 a 1990. Os elementos que, para nós, caracterizam a cultura acadêmica - ações pedagógicas, métodos de ensino, formas de avaliação e materiais didáticos utilizados pelos professores - articulam-se àqueles característicos, também, da cultura escolar, pois se fazem presentes, diretamente, nas ações educativas que se desvelam no interior das salas de aula, seja na escola ou na universidade.

Forquin (1993, p. 167) esclarece que a cultura escolar é constituída pelo "conjunto de conteúdos cognitivos e simbólicos que selecionados, organizados, normalizados, rotinizados, sob efeitos de imperativos de didatização, constituem habitualmente o objeto de transmissão deliberada no contexto das escolas" (grifo do autor). Faria Filho et al. (2004, p. 146) pontuam que para Forquin

essa seleção decorria de fatores sociais, políticos e ideológicos que, de acordo com o autor, comportavam algo de arbitrário e de constante questionamento da escola legada pelos antepassados, e se realizava pelo entrecruzamento de ações institucionais (currículo oficial), docentes (currículo real) e discentes (currículo aprendido). Fazia-se acompanhar, ainda, de uma transformação do conhecimento produzido pela academia. E, nesse sentido, não apenas recortava saberes e materiais culturais disponíveis em um dado momento na sociedade, mas efetuava a reorganização e reestruturação desses saberes, perante a necessidade de transposição didática.

Para Viñao Frago (1995), a cultura escolar abrange as diversas manifestações das práticas instituídas no interior das escolas, passando de alunos a professores, de normas a teorias. Ela engloba tudo o que se passa no interior da escola.

[...] Alguém dirá: tudo. E sim, é certo, a cultura escolar é toda a vida escolar: fatos e ideias, mentes e corpos, objetos e condutas, modos de pensar, dizer e fazer. $\mathrm{O}$ que acontece é que nesse conjunto há alguns aspectos que são mais relevantes do que outros, no sentido de serem elementos organizadores que a conformam e definem (Viñao Frago, 1995, p. 69, tradução nossa).

As conceituações de Julia e Forquin acerca das culturas escolares são dirigidas explicitamente às escolas primária e secundária, mas, de acordo com Faria Filho et al. (2004), Viñao Frago estende o conceito às instituições escolares em geral, incluindo as de ensino universitário. Assim, há uma ampliação das possibilidades de estudos no campo da história das instituições, já que se torna possível "atribuir a cada escola, colégio e universidade uma singularidade" (Faria Filho et al., 2004, p. 148). Esse é o nosso entendimento. Não pretendemos estabelecer uma diferenciação entre a cultura escolar e a cultura acadêmica, mas, sim, dar visibilidade às peculiaridades dessa última, quais sejam: as negociações burocráticas e administrativas gerais que ocorrem em qualquer instituição educativa, por exemplo, o controle e preenchimento de formulários e ementários, ações e decisões de conselhos departamentais e de curso, estabelecimento de horários e carga horária, questões sindicais e salariais, forma de distribuição de poderes entre direção, mantenedores, 
DOI: https://doi.org/10.20396/zet.v27i0.8654227

professores, alunos e demais funcionários. Todos esses elementos não necessariamente participam, diretamente, da sala de aula, mas circunscrevem toda ação didática e pedagógica no interior de um curso e/ou instituição.

Dadas as questões contextuais de natureza socioeconômica, o perfil dos professores e estudantes, os interesses particulares dos grupos que a mantêm e/ou gerenciam, cada instituição de ensino superior tem uma cultura acadêmica singular. Neste trabalho, consideramos a importância de analisar elementos da cultura acadêmica do curso que focalizamos a fim de compreender que Matemática se ensinava e como essa ação pedagógica se realizava, como os acadêmicos aprendiam e como se tornaram professores de Matemática, além de conhecer as tendências teóricas e pedagógicas subjacentes à prática dos professores. Em particular, usamos, para a análise aqui empreendida, juntamente com as fontes orais que constituímos (Almeida, 2015), escritos próprios da gestão acadêmica das disciplinas do curso, como os planos para ministrar essas disciplinas e seus diários de classe, bem como livros didáticos relacionados em suas bibliografias.

Iniciamos nossa exposição a partir dos planos para algumas disciplinas do curso no período de 1968 a 1990.

\section{Métodos de Ensino e Formas de Avaliação: o que "dizem" os planos de curso e os relatos dos professores?}

No intuito de compreender que fundamentos teóricos e metodológicos norteavam a formação de professores de Matemática no curso investigado, examinamos 21 planos elaborados para algumas disciplinas cujos nomes são informados a seguir, juntamente com o ano curricular em que seriam lecionadas e os anos letivos para os quais foram propostas: Desenho Geométrico ( $1^{\circ}$ ano/1968); Fundamentos I (1 $1^{\circ}$ ano/1974) $)^{5}$; Geometria Analítica Plana (1 ${ }^{a}$ série/1974); Álgebra Moderna (2º ano/1971); Geometria Analítica (2ªno/1973 e 1974); Fundamentos II (2 ${ }^{\mathrm{a}}$ série/1974); Cálculo Diferencial e Integral (2 $2^{\mathrm{a}}$ série/1974); Matemática II (2 ${ }^{\circ}$ ano/1982); Estatística I (2 $2^{\text {a }}$ série/1990); Fundamentos (3ªno/1971) ${ }^{6}$; Cálculo Diferencial e Integral ( $3^{\mathrm{a}}$ série/1974); Prática de Ensino de Matemática (3 ${ }^{\mathrm{a}}$ série/1990); Psicologia da Aprendizagem (4 $4^{\mathrm{a}}$ série/1974) ${ }^{7}$; Prática de Ensino (4º ano/1971 e

\footnotetext{
${ }^{5}$ Esse foi o nome da disciplina registrado no Plano de Curso, sob a responsabilidade da professora Walquíria Gonçalves dos Santos, embora no Parecer no 45/1968 referente a "Pedido de autorização de cursos", emitido pelo Conselho Estadual de Educação, em que aparece o plano curricular proposto para o curso de Matemática, esteja registrado o nome da disciplina como Fundamentos de Matemática Elementar (na $1^{\text {a }}$ série).

${ }^{6}$ Esses foram o nome da disciplina e o ano do curso em que se localizava registrados no Plano de Curso, embora no Parecer no 45/1968 relativo a "Pedido de autorização de cursos" emitido pelo Conselho Estadual de Educação, em que aparece o plano curricular proposto para o curso de Matemática, o nome da disciplina seja Fundamentos de Matemática Elementar (na $1^{\mathrm{a}}$ e $2^{\mathrm{a}}$ séries). Não consta o nome do professor responsável pela disciplina.

${ }^{7}$ Esses, também, foram o nome da disciplina e o ano do curso em que se localizava registrados no Plano de Curso, sob a responsabilidade do professor Nebson Escolástico da Paixão, embora no Parecer no 45/1968 do Conselho Estadual de Educação, em que figura o plano curricular proposto para o curso de Matemática, apareça o nome da disciplina como Psicologia da Educação: Adolescência, Aprendizagem (na $4^{\mathrm{a}}$ série).
} 
DOI: https://doi.org/10.20396/zet.v27i0.8654227

1974); Cálculo Numérico (4 $4^{\mathrm{a}}$ série/1973, 1974 e 1986); Cálculo Diferencial e Integral (4 série/1974); Cálculo Diferencial (4º ano/1978).

Todos os planos apresentam o ano civil, o nome da disciplina e o ano ou série do curso em que se localizava. Em 17 deles, há o registro da carga horária da disciplina que difere, ora para mais ora para menos, daquela apresentada na Proposta Curricular de Matemática por meio do Parecer $n^{\circ} 45 / 68$, referente a "Pedido de autorização de cursos", emitido pelo Conselho Estadual de Educação. Por exemplo, no plano da disciplina de Fundamentos ( $3^{\circ}$ ano, 1971) está anotada uma carga horária de 194 horas. Na proposta curricular, com o nome de Fundamentos de Matemática Elementar, ela figura com 120 horas na $1^{\text {a }}$ série e 90 horas na $2^{\text {a }}$ série. A disciplina Psicologia da Aprendizagem aparece com 32 horas no plano de curso e com 90 horas na proposta curricular.

O que concerne ao conteúdo das disciplinas elencadas anteriormente será tratado em outro momento e trabalho, dada a extensão merecida da análise das ementas. Se pensarmos, inicialmente, sobre o modo como os conteúdos das disciplinas de Álgebra Moderna e de Fundamentos de Matemática são tratados em diferentes cursos de Licenciatura, veremos que há casos, por exemplo, em que Fundamentos de Matemática referem-se ao tratamento dos conteúdos de matemática básica, presentes no ensino médio, com um formalismo um pouco mais acentuado apenas, ao passo que há ementários de Fundamentos de Matemática que implicam um tratamento matemático mais próprio do que se conhece por Fundamentos na prática científica profissional da Matemática. Incluem-se aí, por exemplo, tópicos de Lógica binária, Lógica Fuzzy, discussões sobre consistência de sistemas formais, os Teoremas de Godel, entre outros. Não realizamos, neste trabalho, esse exercício de análise, pois num primeiro olhar verificamos que há diferentes modos como os conteúdos são tratados se os compararmos em matrizes curriculares de diferentes cursos de licenciatura.

Nos relatos de nossos depoentes, percebemos poucas menções às disciplinas pedagógicas e os planos nos mostraram que a carga horária predominante era das disciplinas de conteúdo matemático, o que atesta que, no modelo de formação docente adotado, como usualmente nos cursos de licenciatura, a formação matemática era muito priorizada em relação à formação pedagógica.

Somente em dois planos figuram a ementa e os pré-requisitos ou requisitos para cursar a disciplina. Ao que nos pareceu, esses itens tinham um caráter muito mais burocrático do que pedagógico, pois, em nossa análise, não identificamos nesses dois planos qualquer relação entre os pré-requisitos e os conteúdos ministrados e/ou objetivos das disciplinas.

Em onze planos, são explicitados os objetivos gerais das disciplinas. Os registros desses objetivos são os mais variados possíveis. Notamos que a redação dos objetivos para as disciplinas Desenho Geométrico e Álgebra Moderna, transcritos a seguir, busca uma aproximação com a futura prática profissional do licenciando em Matemática.

Desenho Geométrico: "Proporcionar condições ao aluno, conhecendo a matéria, de transmiti-la como futuro professor de Ensino Médio; fazer coordenação entre as cadeiras de Geometria Analítica e Fundamentos da Matemática Elementar para sua melhor compreensão. 
DOI: https://doi.org/10.20396/zet.v27i0.8654227

Álgebra Moderna: "Não se visa somente dar matéria, mas fazer com que o aluno compreenda o que lhe está sendo ensinado; adquirir destreza matemática e automatismo necessário no término do curso; preparar o aluno para que, ao término do curso, seja um profissional competente. A boa didática, as atitudes corretas no tratamento com os alunos e no ensinamento da matéria".

Aqui, verificamos a presença de uma intenção declarada, no programa de ensino, de aproximar as práticas profissionais do futuro professor das disciplinas da matriz do curso de formação. A disciplina Álgebra Moderna é caracterizada, usualmente, nos programas de ensino universitário, como formal e árida do ponto de vista das aplicações a situações "reais" ou mesmo a situações de sala de aula do ensino médio. Portanto, podemos inferir que se trata, mais uma vez, de uma enunciação mais burocrática que pedagógica ou efetiva da instituição que mantém o curso e aprovou os planos.

Outro aspecto que nos chamou a atenção foi o registro de objetivos de área cognitiva e afetiva em sete planos, ou seja, em aproximadamente $30 \%$ do total de planos analisados. A nosso ver, tais objetivos pouco se relacionam à afetividade. Assim, há argumentos que colocam na área denominada "afetiva" objetivos como: "aprimorar os conceitos que os alunos têm de fundamento; fazer com que o aluno estabeleça relações entre os conhecimentos adquiridos e os problemas da vida cotidiana" (Prof. Egídio Cordeiro Aquino, disciplina Fundamento II (sic), 2 ${ }^{\mathrm{a}}$ série/1974); "formar hábitos de correção, rigorismo e precisão; desenvolver habilidade de empregar o pensamento lógico e a visão de conjunto" (Prof ${ }^{a}$ Mariza Monteiro Guimarães, disciplina Geometria Analítica, $2^{\circ}$ ano/1974); "desenvolver o raciocínio e fazer com que o aluno consiga resolver os problemas que surgem não só na vida prática como em outras ciências" (Prof. Francisco Bastos Gil, disciplina Cálculo Diferencial e Integral, $3^{\mathrm{a}}$ série/1974).

Num dos planos, o de Geometria Analítica Plana (1ª série/1974), aparecem objetivos formativos e informativos:

"Continuar desenvolvendo ou criar no aluno os seguintes hábitos e/ou habilidades: de compreensão, raciocínio e análise; de esquematização e ordem; de interpretações das equações através de gráficos; de resolução das provas e testes com ordem e capricho; de compreensão de que a sequência, em matemática, é fator importantíssimo" (objetivos formativos).

"Fazer o aluno compreender: a importância da Geometria analítica, tendo em vista a sua larga aplicação em cálculo diferencial e integral; a necessidade de recorrer à biblioteca e não se prender unicamente ao autor adotado como base; o fato de estar aprendendo para ensinar e não para si só" (objetivos informativos).

Não é clara para nós a distinção entre os dois tipos de objetivos nesses planos. Por exemplo, "a necessidade de recorrer à biblioteca e não se prender unicamente ao autor adotado como base" pareceu-nos mais a recomendação de uma atitude (portanto algo de caráter formativo) do que uma intenção informativa.

Ao que parece, havia uma grande preocupação com os métodos de ensino (técnicas Zetetiké, Campinas, SP, v.27, 2019, p.1-19 - e019005

ISSN 2176-1744 
DOI: https://doi.org/10.20396/zet.v27i0.8654227

didáticas, procedimentos e atividades de aprendizagem - conforme registros dos professores), pois catorze planos, aproximadamente $75 \%$, apresentam detalhadamente a previsão de como seriam executadas as aulas. Constam desses 14 planos as seguintes técnicas didáticas e procedimentos: "aulas expositivas e dialogadas; debates e Exercícios; grupo de discussões e pesquisa programada. Método: Intuitivo e Dedutivo. Pesquisas, Análise conjunta de problemas, Trabalhos em equipe. Preleção com auxílio do quadro negro, estudo dirigido, pesquisa. Preleção mista, Painel simples, Método da Redescoberta. Trabalhos em classe, revisões, pesquisas. Resolução de exercícios em aula, projeto. Método expositivo havendo, entretanto, um mesclado com o heurístico". Procedimentos: "exposição da matéria; problemas e exercícios. Aulas práticas e eficientes permitindo ao aluno a assimilação perfeita da matéria; aulas motivadas e dialogadas para serem melhor captadas. Discussão programada, trabalhos".

Podemos depreender algumas prescrições da época para a formação dos professores de Matemática, quais sejam: ensinar é apresentar e explicar o conteúdo numa exposição clara, detalhada, com exemplos, de modo que o estudante possa entender melhor o que está sendo transmitido; para ser um bom docente, é necessário explicitar o conteúdo com suas definições e sínteses, ter boa oratória e boa didática - elementos essenciais à competência. Tais prescrições nos remetem, conforme assinala Anastasiou (2004), ao modelo jesuítico presente na colonização do Brasil, em que era utilizado um manual de ensino, o Ratio Studiorum, composto de três passos básicos para a execução de uma aula: "preleção do conteúdo pelo professor, levantamento de dúvidas dos alunos e exercícios para fixação, cabendo ao aluno a memorização para a prova" (Anastasiou, 2004, p. 12). Nessa perspectiva, a transmissão de conceitos é tomada como ensino e o professor como fonte do saber, portador da verdade.

Conforme relato de uma das entrevistadas, embora os alunos das primeiras turmas já atuassem como professores de Matemática no ensino secundário, cursar a graduação em Matemática trazia segurança para ministrar os conteúdos e, ainda, conhecimento aprofundado das teorias e autores de maior prestígio à época. Isso nos remete a uma reflexão sobre o tipo de professor ou o tipo de aulas que eram ministradas, pois os depoentes que estudaram nas décadas de 1960 e 1970 deixam entrever que o curso era muito rígido, assim como seus professores.

Era manifesta a necessidade de transmitir bem os conteúdos, de repetir exercícios, de seguir as prescrições do livro, de fazer boas demonstrações, de resolver problemas de modo correto e competente para a consolidação do conhecimento matemático, de acordo com nossos colaboradores. Tais aspectos nos direcionam para a tendência liberal tecnicista (da segunda metade do século XX), que tem como foco a preparação de sujeitos competentes para o mercado de trabalho. Nela, os procedimentos do professor e as técnicas que ele utiliza são essenciais para a eficiência do ensino, de modo que o estudante receba, adequadamente, as informações e conceitos (Libâneo, 1994; Saviani, 2003).

Luckesi (2005) esclarece que a tendência tecnicista se insere na Pedagogia Liberal, que, representando uma visão educacional mais ampla, lega à escola a função de preparar o estudante para o exercício de papéis sociais, com base em suas aptidões e habilidades, 
DOI: https://doi.org/10.20396/zet.v27i0.8654227

cabendo a este assimilar as normas e valores sociais vigentes, por meio de sua cultura própria. Essa tendência representa, portanto, um sistema orgânico e funcional que recorre a técnicas e recursos metodológicos específicos para moldar o comportamento humano.

$\mathrm{O}$ professor $\mathrm{Gil}^{8}$ explicou como agia quando resolvia um problema no quadro.

Quando ia resolver um problema no quadro, eu falava o tempo inteiro mostrando como é que eu estava raciocinando, como é que deveria ser o raciocínio de uma pessoa diante de um problema. [...] Então eles começaram a receber essas informações e meu comportamento, minha metodologia serviu de modelo. Eles começaram a mudar o jeito de ministrar as suas aulas (Gil, Entrevista, 2013).

A professora Mariza Guimarães sugeriu que o professor Gil foi um bom modelo de organização e de metodologia apropriada para o ensino de Matemática.

Procurava... Organizar bem o quadro de uma maneira bem clara, bem didática, com isso a gente se preocupava muito... As aulas, naquela época, eram somente com o quadro negro e o giz. Então, a gente utilizava muito bem esse instrumento de trabalho e os exercícios. Não se admite estudar Matemática sem fazer exercícios, porque são eles que vão pôr à prova a teoria aprendida e a aplicação daquela teoria na prática... (Guimarães, Entrevista, 2013).

A professora Dilma Mourão enfatizou a importância da resolução de exercícios para a aquisição de uma boa base matemática.

Ficava até meia-noite resolvendo exercícios do Granville. A gente estudava demais, resolvia exercícios demais, e isso era bom porque dava muita base. Eu notei que a partir do momento em que eu comecei a fazer faculdade eu tinha muito mais bagagem, tinha muito mais competência para fazer o meu trabalho (Mourão, Entrevista, 2012).

Também o professor João Barbosa de Souza destacou:

Eu, às vezes, ficava noites e noites, semanas e semanas tentando resolver um problema... Quando eu resolvia, era como tirar na loteria (Souza, Entrevista, 2013).

Nos métodos utilizados para o ensino de Matemática na graduação, há indícios, conforme já dissemos, da tendência liberal tecnicista, presente especialmente no final da década de 1960 e início da década de 1970. A partir das reformas do governo da ditadura militar, nesse período, foram implantados o programa de desenvolvimento socioeconômico "Aliança para o Progresso" 9 " e acordo "MEC-USAID ${ }^{10 ",}$ resultado de convênio de

\footnotetext{
${ }^{8}$ Trechos das narrativas de nossos entrevistados são enfatizados pelo uso de itálicos.

9 A “Aliança para o Progresso" constituía-se num programa de ajuda externa, voltado para a América Latina, criado em 1961 e tinha como principal objetivo promover o desenvolvimento econômico por meio da colaboração financeira e técnica aos países latino-americanos (Bordignon, 2011).

${ }^{10}$ Nos anos 1960 foram assinados acordos entre o Brasil e a USAID (Agência dos Estados Unidos para o Desenvolvimento Internacional - tradução nossa). Criada no período da guerra fria, essa agência norteamericana tinha como objetivo assessorar países subdesenvolvidos. Desse modo, aqui no Brasil, o acordo MECZetetiké, Campinas, SP, v.27, 2019, p.1-19 - e019005

ISSN 2176-1744
} 
DOI: https://doi.org/10.20396/zet.v27i0.8654227

cooperação estabelecido entre o Brasil e os Estados Unidos. Foi, também, nesse período, que ocorreu a oficialização do modelo tecnicista por meio da promulgação das leis 5.540/68, que reformulava o ensino superior, e 5.692/71, que configurava uma nova estrutura ( $1^{\circ}$ e $2^{\circ}$ graus) para o ensino antes organizado em níveis primário, ginasial e colegial ou técnico.

Segundo a professora De Lourdes:

Era uma época da escola tecnicista, então, eles, os matemáticos daqui, gostavam do giz colorido, do quadro bem escrito, e não existiam as ferramentas de hoje. O compasso era feito de madeira, réguas grandes, esquadros... Então eles queriam muito aprender a utilizar tudo o que colaborasse para uma boa aula expositiva. [...] Aqueles alunos tinham a preocupação de entender melhor o processo de aprendizagem, tinham o objetivo de fazer com que os alunos deles gostassem da matemática (Paixão, Entrevista, 2012).

$\mathrm{Na}$ tendência tecnicista, há a "predominância de situações modelares, geralmente apostiladas, a serem aplicadas pelo professor e assimiladas e internalizadas pelos alunos" como meros executores de um processo concebido por outrem (Anastasiou, 2004, p. 8). Nela é a marcante a preocupação com o controle externo e comportamental (por parte de pedagogos e/ou coordenadores de curso); o treino de habilidades e a sequência em que devem ser apresentados os conteúdos sob a forma de instrução programada, capacitando o estudante a resolver exercícios ou problemas padronizados. Na matemática escolar, prioriza-se a utilização de fórmulas e definições, o que acarreta prejuízo para a essência e o significado dos conceitos.

Em sua entrevista, o professor João Barbosa de Souza destacou como um valor a dificuldade da Matemática e assinalou diferenças entre os alunos do passado e os daquele momento.

A partir do momento em que facilitaram o ensino de Matemática, acabaram com aquelas pessoas, com aquelas inteligências que estavam buscando estudar Matemática. Então, tornou-se uma Matemática fácil... Mas a Matemática não é nada fácil. A pessoa tem que começar estudando tendo a certeza de que ela é difícil, não é fácil. Mas tinha muitas pessoas que, naquela época, na minha época, gostavam de estudar, gostavam do difícil... Hoje, todo mundo procura o fácil e se é fácil não vai chegar a lugar nenhum, na Matemática não vai conseguir nada. [...] Desde a minha época, quem gostava de Matemática era, tipo assim, metido, era o cara chamado de inteligente (Souza, Entrevista, 2013).

Subjacente às concepções manifestadas nas falas de nossos entrevistados está a ideia da importância da formação especialista matemático. Para muitos professores, a Matemática é considerada como "domínio das verdades absolutas que se dispõem em uma estrutura complexa, onde imperam a ordem e o rigor" (Cury, 1994, p. 224). Por isso mesmo, adotam uma postura autoritária e dogmática, articulando a dificuldade dos estudantes em determinados conteúdos à falta de talento ou inteligência para aprender a Matemática.

USAID consistia em garantir a vigência do sistema capitalista e transferir as concepções e a organização social, política, econômica e educacional que prevalecia nos Estados Unidos (Pina, 2008). 
DOI: https://doi.org/10.20396/zet.v27i0.8654227

Entretanto, podemos constatar que, levando em conta as dificuldades, os professores que entrevistamos se esforçavam para mostrar aos alunos conexões entre os conteúdos abordados, buscando, talvez, conseguir que os estudantes percebessem um sentido naquilo que era ensinado no curso. O professor Sebastião Alves de Souza, que se considera vocacionado para o ensino, descreveu sua metodologia de ensino, valorizando-a em relação a recursos tecnológicos disponíveis na atualidade:

Utilizo a metodologia tradicional... Não gosto de canhões, de computação, de Skype... Essas coisas bonitinhas demais... Como eu ensino a ler Matemática, tenho que escrever muito no quadro, porque eu tenho que fazer passo a passo para o aluno ler. [...] Então sou tradicional no sentido do cuspe e giz. Mas, em todo momento, tento fazer uma relação com o que eles já viram e com o que eles vão atuar... Tento contextualizar minha disciplina... Uma questão que eles sempre perguntam: "Para que estou estudando isso aqui se não vou dar aula específica disso?". Tento mostrar que isso aqui tem a ver com aquilo ali... Para ensinar você tem que saber além daquilo que ensina... E não por baixo ou no meio...(Souza, Entrevista, 2013).

Retomando a análise dos planos de curso, verificamos que a distribuição do tempo para a execução das disciplinas é apresentada na maioria (17 em 21), enquanto apenas quatro trazem o registro dos seguintes recursos materiais para a viabilização das aulas: quadro negro, giz, livros didáticos, régua, papel mimeografado, tabelas.

Treze dos planos apresentam os instrumentos para avaliação dos alunos nas diversas disciplinas. São instrumentos variados, mas comuns, predominando as provas escritas. Contudo, há alguns casos em se preveem seminários, exercícios, participação nas aulas, autoavaliação e trabalhos adjetivados de muitas formas: de aplicação, de estágio, de pesquisa.

Ex-alunos que posteriormente foram docentes do curso evidenciaram, em suas lembranças, que tanto os instrumentos quanto os critérios da avaliação praticada eram aceitos sem questionamento e até bem vistos. Foi o caso dos professores Edson e Mariza Guimarães.

A gente aprendia muito, achando que estava resolvendo um problema, mas o leque de possibilidades, estratégias, era muito grande, aprendíamos muitos outros conceitos. [...] $O$ professor Gil sabia muito bem, era um mestre... As provas eram rigorosas. Ele cobrava mesmo! Com muita rigidez! Não só ele, mas, os outros também. Ele não se importava de dar zero. O aluno tinha que demonstrar conhecimento. Se não sabia era zero mesmo! (Edson Guimarães, Entrevista, 2013).

A professora Mariza Monteiro Guimarães comentou as práticas avaliativas do professor Francisco Gil, mostrando apreço por elas, visto que provocavam esforços dos estudantes:

Do conteúdo de geometria ele exigia uma dissertação e, por exemplo, quando caía um ponto sobre triângulos, você tinha que falar tudo sobre triângulos... [...] Havia, também, os exercícios inéditos que só na hora da aula eles eram apresentados para a gente. Dentro do conteúdo aprendido, você tinha que desenvolver aquele exercício até provar aquela verdade que foi proposta. Era um método muito interessante, fazia a gente pensar muito, Zetetiké, Campinas, SP, v.27, 2019, p.1-19-e019005

ISSN 2176-1744 
tinha gente que chegava a suar (Mariza Guimarães, Entrevista, 2013).

Podemos inferir que a avaliação praticada no curso de Matemática privilegiava a retenção e reprodução dos conhecimentos "aprendidos". A menção aos "zeros" foi recorrente e naturalizada pelos antigos estudantes. A proposição de exercícios completamente distintos dos usuais deixa manifesta uma ênfase no desempenho individual, em determinada concepção de competência acadêmica e na competitividade entre os estudantes. Nossos colaboradores não se referiram à realização desses exercícios desafiadores em grupo, com as soluções partindo de vários estudantes e sendo compartilhadas e sistematizadas sob a coordenação do professor.

Um aspecto curioso é que também eram aplicadas provas dissertativas nas quais, segundo os entrevistados, todos os tópicos trabalhados em classe deveriam ser contemplados.

Da análise dos planos de curso, foi possível depreender que épocas e orientações (das coordenações do curso) diferentes se associavam a modificações nesses documentos. Porém, um traço marcante em todos os planos é a ênfase nos conteúdos cujo conhecimento se propunha verificar, invariavelmente, mediante trabalhos, exercícios e provas.

\section{Fazeres pedagógicos cotidianos: diários de classe e testemunhos pessoais}

Os diários de classe se constituem em importantes instrumentos para registrar o fazer pedagógico do professor em sala de aula, ainda que se deva considerar as limitações advindas da natureza dessa fonte. Afinal, trata-se de documentos exigidos no cotidiano das instituições de ensino nos quais são muito limitados os espaços para registros que, necessariamente, são extremamente resumidos.

O exame dos 13 diários de classe de quatro décadas (1960, 1970, 1980 e 1990) a que tivemos acesso nos remete à visualização do currículo no sentido empregado por Silva (2014, p. 16) ao discorrer sobre as "teorias tradicionais" que o envolvem e que se pretendem "neutras, científicas, desinteressadas". Nessas teorias, os conhecimentos e os saberes dominantes concentram-se em questões técnicas. $\mathrm{O}$ foco das teorias tradicionais do currículo é a organização do conhecimento inquestionável. Nelas estão imbricadas relações de poder, conduzindo os sujeitos a verem a educação numa determinada perspectiva (Silva, 2014).

Conseguimos identificar o conteúdo ou matéria lecionados e, em certa medida, como os professores desenvolviam suas práticas pedagógicas com o objetivo de formar bons professores de Matemática na perspectiva das teorias tradicionais do currículo. Há uma grande variedade na forma de preenchimento desses documentos, que são mais ou menos pormenorizados de acordo com o perfil do docente responsável pela disciplina. Como exemplos, apontamos o diário da disciplina "Fundamentos da Matemática", de 1968, que traz um registro minucioso do conteúdo ministrado, e o diário da disciplina "Cálculo Diferencial e Integral” de 1980, no qual aparece repetidas e seguidas vezes a expressão: integrais diretas e exercício.

Nos registros do diário de 1968 da disciplina Fundamentos da Matemática há indícios 
DOI: https://doi.org/10.20396/zet.v27i0.8654227

de que o professor apresentava os conceitos relacionados à disciplina e, posteriormente, a cada duas ou três aulas propunha problemas e/ou exercícios de verificação do conteúdo estudado. Já no diário de 1980 da disciplina Cálculo Diferencial e Integral, nas seis aulas visibilizadas, há registro, nos dias 14 e 21 de junho, da abordagem de "Integrais diretas", enquanto no dia 28 do mesmo mês está anotada a realização de aulas de exercícios. Essas anotações nos levam a crer em práticas de ensino tradicionais no sentido de se basearem no binômio "transmissão do conteúdo-prática de exercícios". Percebemos sintonia com a conceituação de Anastasiou (2004) para o método tradicional: os passos seguidos visam ao registro do símbolo, via memorização, enfatizando a aula expositiva e os exercícios de repetição, ou questionários pontualmente corrigidos e decorados.

Podemos estabelecer uma relação entre os registros dos diários de classe e o contexto histórico em que foram desenvolvidos. No Brasil pós-1964, o Sistema Nacional de Ensino foi reorganizado tendo em vista a racionalização dos aspectos administrativo e pedagógico. A questão central do ensino passou a ser o planejamento cuidadoso de todas as tarefas a serem executadas. Desse modo, prescrevia-se que o planejamento fosse executado numa perspectiva exclusivamente técnica e ocupasse lugar de destaque nos manuais e programas de ensino. "A racionalização do processo aparece como necessidade básica para o alcance dos objetivos do ensino" (Martins, 1998, p. 148).

A ênfase na realização de muitos exercícios e, por vezes, a concordância com a eficiência dessa prática para a aprendizagem foram constantes nas narrativas de nossos colaboradores.

Para aprender, mesmo, você tem que saber resolver os exercícios. No livro de Granville tinha cada exercício, que ficávamos dois, três dias para achar a solução... E isso demanda tempo e dedicação... E tínhamos que resolver os exercícios considerando a teoria dada pelo professor. Havia os livros, também... A gente tinha que estudar o Granville e outros livros para criar elementos suficientes para conseguir resolver os exercícios que eram propostos. E nas provas poderiam cair exercícios inéditos desse tipo... Se você não treinasse antes, não conseguiria fazer a prova (Mariza Guimarães, Entrevista, 2013).

Nós fazíamos muitos exercícios, utilizávamos a técnica de fazer as contas sem muita teoria (Sebastião Souza, Entrevista, 2013).

Depois de formados e na condição de professores do curso, tanto Mariza como Sebastião mantiveram, em seus fazeres docentes, a prática de propor aos alunos muitos exercícios, exatamente como haviam feito seus professores. Esses docentes, no entanto, sublinharam sua preocupação, cada um à sua maneira, em aproximar os estudantes dos conceitos matemáticos.

Percebi que ficava melhor para eles aprenderem o conteúdo e depois aplicarem na prática, através dos exercícios. Eu sempre tive isso, de me preocupar em mostrar ao aluno a aplicação prática dos conteúdos. Primeiro eu mesma pensava... Como é que eu vou usar isso? Onde é que tem isso que a gente utiliza? Porque, realmente, tem gente que não gosta da Matemática por isso... Fala assim: "Pra que estudar isso? Eu nunca vou precisar disso, 
DOI: https://doi.org/10.20396/zet.v27i0.8654227

eu não vou entender!". Então eu sempre pensei em falar sobre a aplicação da Matemática para os meus alunos (Mariza Guimarães, Entrevista, 2013).

Então, a aluna cometeu alguns equívocos nas continhas... A prova valia vinte. Ela tirou vinte, porque não é isso que estou cobrando... Conta até eu ia errar. Falo com eles... Exercícios do livro até eu não vou saber resolver... Há exercícios que pode ser que você não saiba resolver... Deve ser uma coisa natural. Tenho que resolver uma certa parte de exercícios, tenho que ter uma certa situação... Mas quando fui entrar na Universidade tive direito de errar 30\%... O tempo de aprendizagem em Matemática, principalmente, acaba sendo mais longo por causa de nossa cultura de que matemática é fazer conta, é exata, numérica... (Sebastião Souza, Entrevista, 2013).

Tais posturas mostram que, no jogo das interveniências mútuas, tanto alunos quanto professores são elementos essenciais na constituição das disciplinas acadêmicas, pois mobilizam saberes e produzem experiências modificadoras dos processos de aprender e ensinar.

A partir da análise dos planos de curso, diários de classe e das entrevistas, reconhecemos uma concepção principal de formação de professores de Matemática presente na criação e implementação inicial do curso: a de que o curso de Matemática deveria ser difícil, com rigor teórico, buscando formar professores certificados e qualificados para atuar de forma eficiente na docência.

\section{Livros e depoimentos: que concepções e imbricações?}

Nossos depoentes disseram que a disponibilidade de livros para estudo e preparação das aulas era muito pequena. O professor Francisco Bastos Gil, por exemplo, declarou utilizar obras de seu acervo pessoal, e deixou claro que eram obras com grande aprofundamento dos conteúdos a serem trabalhados no curso.

Sobre as obras que eu utilizava para preparar minhas aulas, posso afirmar que oitenta por cento delas eram de origem estrangeira. Aliás, eu as carrego até hoje... São livros russos, franceses e americanos... Esses livros são muito mais profundos do que os que a gente tem aqui... (Gil, Entrevista, 2013).

Já a professora Maria de Lourdes Ribeiro Paixão considerou que o acervo da instituição era suficiente para atender as necessidades dos estudantes:

A biblioteca era simples, formada por livros que os primeiros professores trouxeram... Indicávamos os mesmos livros que tínhamos usado na Universidade. Mas, apesar disso, penso que a biblioteca tinha o básico. Ela era muito utilizada. O espaço físico era dividido com estantes de um lado e de outro havia um espaço grande para estudo. Me lembro bem que a biblioteca ficava, constantemente, lotada de alunos. O número total de alunos de cada curso era pequeno, então, o acervo que existia atendia, eram só os nossos livros e apostilas (Paixão, Entrevista, 2012).

Entretanto, vários ex-alunos, depois professores do curso, nos possibilitaram notar que 
DOI: https://doi.org/10.20396/zet.v27i0.8654227

um elemento dificultador era a inexistência ou o número reduzido de obras de autores de prestígio na biblioteca. Foi necessário recorrer aos livros dos docentes, à reprodução e à aquisição dessas obras em Belo Horizonte ou em outras cidades. É ilustrativo o seguinte trecho:

Quanto à biblioteca, me lembro que o acervo era muito pobre, principalmente, na área da Matemática. Não havia nada, não! A gente ainda encontrava alguma coisa de Didática, Estrutura, Psicologia, mas Matemática... Nada! E era difícil até pra comprar. Tínhamos que ir a Belo Horizonte comprar. A gente estudava demais e pegava tudo quanto é livro que a gente podia encontrar... Naquela época, realmente, não era muito fácil estudar o Granville, a Coleção Schaum, Piskounov... (Durães, Entrevista, 2013).

Foi destacado, em muitas narrativas, que os livros disponíveis eram insuficientes para todos os alunos e relatado que a biblioteca não possuía os clássicos estudados nos cursos de Matemática, um Piskounov, que era um livro espanhol, um Granville, um Leithold não existia aqui [...], eram poucos que tinham os livros... A gente estudava em equipe (Nuzzi, Entrevista, 2013).

Era o básico do básico. Tínhamos alguns livros de Cálculo, Álgebra, Introdução à Matemática... No máximo dois exemplares de cada obra. No mais, tirávamos xerox... (Ferreira, Entrevista, 2013).

Das obras utilizadas nas aulas, foram citadas duas da Coleção Schaum - Estatística, de Spiegel, e Cálculo, de Frank Ayres Júnior; os Tomos I e II de Cálculo Diferencial e Integral, de Piskounov; Cálculo com Geometria Analítica, de Leithold; Cálculo, de Lang; Elementos de Cálculo Diferencial e Integral, de Granville, e o Guia de Matemática, de Ary Quintella. A tabela a seguir traz informações sobre essas obras ${ }^{11}$.

Vale destacar que encontramos, nos trabalhos acerca da criação de cursos e da formação de professores de Matemática de Baraldi (2003) sobre a região de Bauru (SP), Fernandes (2011) sobre o estado do Maranhão, Martins-Salandim (2012) sobre o estado de São Paulo e Macena (2013) sobre João Pessoa (PB), referências sobre a circulação dessas obras.

\footnotetext{
${ }^{11}$ Realizamos pesquisas na Biblioteca Central da Universidade Estadual de Montes Claros (Unimontes) e nos sites das editoras a fim de identificar o número de edições e a data da $1^{\mathrm{a}}$ edição da obra.
} 
DOI: https://doi.org/10.20396/zet.v27i0.8654227

Tabela 1 - Principais obras utilizadas nos cursos de Matemática (décadas de 1960, 1970, 1980).

\begin{tabular}{|c|c|c|c|c|c|}
\hline $\begin{array}{c}\text { NOME } \\
\text { DA } \\
\text { OBRA }\end{array}$ & AUTOR & EDITORA & $\begin{array}{l}\text { NÚMERO } \\
\text { DE } \\
\text { EDIÇÕES }\end{array}$ & $\begin{array}{c}\text { DATA DA } \\
\text { PRIMEI } \\
\text { RA } \\
\text { EDIÇÃO }\end{array}$ & $\begin{array}{c}\text { CIRCULA } \\
\text { ÇÃO EM } \\
\text { OUTROS } \\
\text { CURSOS DE } \\
\text { MATEMÁTI } \\
\text { CA DA } \\
\text { ÉPOCA }\end{array}$ \\
\hline $\begin{array}{c}\text { Estatística - } \\
\text { Coleção } \\
\text { Schaum } \\
\end{array}$ & SPIEGEL, Murray R. & $\begin{array}{c}\text { Editora McGraw } \\
\text { Hill do Brasil } \\
\text { Ltda } \\
\end{array}$ & Três & 1967 & Não \\
\hline Cálculo & AYRES JR, Frank. & Editora Bookman & Cinco & 1961 & Sim \\
\hline $\begin{array}{c}\text { Tomo I de } \\
\text { Cálculo } \\
\text { Diferencial e } \\
\text { Integral } \\
\end{array}$ & $\begin{array}{c}\text { PISKOUNOV, } \\
\text { Nikolai Semenovich. }\end{array}$ & $\begin{array}{l}\text { Editorial Mir } \\
\text { Moscou }\end{array}$ & Doze & 1970 & Sim \\
\hline $\begin{array}{l}\text { Tomos II de } \\
\text { Cálculo } \\
\text { Diferencial e } \\
\text { Integral }\end{array}$ & $\begin{array}{c}\text { PISKOUNOV, } \\
\text { Nikolai Semenovich. }\end{array}$ & $\begin{array}{l}\text { Editorial Mir } \\
\text { Moscou }\end{array}$ & Oito & 1970 & Sim \\
\hline $\begin{array}{c}\text { Cálculo com } \\
\text { Geometria } \\
\text { Analítica }\end{array}$ & LEITHOLD, Louis. & $\begin{array}{c}\text { Editora } \\
\text { HARBRA Ltda. }\end{array}$ & Seis & $\begin{array}{c}1968 \\
\text { Reimpressa } \\
\text { em } \\
1968,1972 \\
\text { e } 1976 . \\
\end{array}$ & Sim \\
\hline Cálculo & LANG, Serge. & $\begin{array}{c}\text { Editora Livros } \\
\text { Técnicos e } \\
\text { Científicos (LTC) }\end{array}$ & Duas & $\begin{array}{c}1969 \\
\text { Reimpressa } \\
\text { em } \\
1970,1971, \\
1972,1973, \\
1975 \text { (duas), } \\
1976, \\
1977 \text { (duas) } \\
\text { e } 1978 . \\
\end{array}$ & Sim \\
\hline $\begin{array}{l}\text { Elementos de } \\
\text { Cálculo } \\
\text { Diferencial e } \\
\text { Integral } \\
\end{array}$ & $\begin{array}{l}\text { GRANVILLE, } \\
\text { William Anthony. }\end{array}$ & Editora Científica & Três & 1961 & Sim \\
\hline $\begin{array}{c}\text { Guia de } \\
\text { Matemática }\end{array}$ & QUINTELLA, Ary. & $\begin{array}{c}\text { Editora } \\
\text { Companhia } \\
\text { Nacional }\end{array}$ & Três & 1952 & Sim \\
\hline
\end{tabular}

Fonte: Elaboração das autoras a partir de pesquisas realizadas em 2014 e 2015.

Com as informações da Tabela 1 e as pesquisas citadas anteriormente, verificamos a presença dos títulos e autores citados por nossos depoentes nos cursos de formação de professores de Matemática da época investigada. Apesar das dificuldades relatadas pelos antigos alunos, notamos que títulos em franca circulação entre os estudantes e professores de cursos de Matemática brasileiros participaram de sua formação acadêmica.

Posteriormente, esses alunos, convertidos em professores, usaram os mesmos livros utilizados na preparação de suas aulas, conforme se constata em planos de curso e depoimentos. O exame dessas obras nos mostrou sua ênfase no desenvolvimento dedutivo e no rigor matemático, que guiavam o trabalho dos professores a partir dos livros. 
DOI: https://doi.org/10.20396/zet.v27i0.8654227

Das falas dos professores, depreende-se que o curso dependia de livros-texto com demonstrações e muitos exercícios, considerados essenciais ao estudo dos conceitos (guia para o professor) e ao bom desempenho na resolução de exercícios e problemas (guia para o aluno).

\section{A título de síntese: o bom professor - seus registros e sua prática}

As práticas pedagógicas mobilizadas pelos professores do curso de Matemática estudado, por constituírem uma cultura acadêmica, foram compartilhadas pelo grupo de formadores e por aqueles ainda em formação. Assim, as prescrições dos planos de curso, os registros dos diários de classe e as escolhas dos livros didáticos implicam permanências e ou transformações nessa cultura. As narrativas que reunimos atestam a influência dos primeiros professores para a construção dos fazeres dos alunos formados que se tornaram docentes do curso, bem como na formação de suas concepções acerca do bom professor e sua prática. Mereceram destaque quanto a essa prática a utilização da exposição oral, a organização do contexto da aula, a explicitação dos objetivos de ensino e o uso de exemplos e de exercícios.

O professor Gil, um dos primeiros docentes do curso disse:

Para ser um bom professor de Matemática, é necessário ter dom. A pessoa tem que saber ensinar, saber transmitir. Eu tive um professor que era um espetáculo de matemático, mas uma porcaria de professor... Ele simplesmente não sabia transmitir. Era competentíssimo. Mas não sabia, nunca soube, nunca teve didática, nunca soube explicar uma coisa óbvia... [...] A maneira de você falar, de explicar conta muito... Agora isso você não aprende. Isso é dom de convencer as pessoas, de detalhar as coisas até elas entenderem (Gil, Entrevista, 2013).

Mariza, primeiramente aluna e depois professora, comentou:

Eu sempre gostei muito de dar aula... Uma coisa com que eu, sempre, me preocupei... Quando eu planejava as aulas era assim, aula de início de um novo capítulo, eu preocupava em mostrar para os alunos o porquê disso, daquilo, para eles sentirem o valor do conhecimento, onde aquilo seria aplicado na vida prática, no dia a dia. Então eu sempre tive preocupação com isso... Eu nunca gostei de chegar com uma fórmula pronta, colocar no quadro e já ir aplicando. Eu mostrava como é que a gente chegou naquela conta, naquela fórmula, naquele resultado... [...] Eu demonstrava como é que os matemáticos pensavam para chegar naquelas fórmulas. Aí os alunos iam entendendo o porquê dos conteúdos... (Mariza Guimarães, Entrevista, 2013).

Nas narrativas de nossos entrevistados sobressaiu a concepção do bom professor como o bom transmissor e conhecedor da matéria, mas há outros elementos sobre os saberes e fazeres desse bom professor que se relacionam aos identificados por Cunha (1992), quais sejam: a articulação dos conceitos trabalhados à vida cotidiana (Professora Maria de Lourdes Ribeiro Paixão); a localização histórica e social do conhecimento (Professora Mariza Monteiro Guimarães); a busca da articulação da teoria com a prática e a estimulação à participação dos estudantes (Professor Edson Crisóstomo dos Santos), dentre outros. 
DOI: https://doi.org/10.20396/zet.v27i0.8654227

Convém destacar que há comportamentos enraizados e reproduzidos por esses professores, apreendidos na convivência com seus próprios professores, mas percebemos, também, a busca por uma educação melhor do que a que consideram ter tido. Para alguns de nossos entrevistados, a ideia de "deve ser assim" foi construída no tempo, lugar e na sociedade, evocando conflitos, contradições e valores socioeducacionais.

Conforme Ponte (1992), as concepções dos professores acerca de seus saberes e fazeres diferenciam-se conforme os níveis de ensino em que exercem a atividade docente ou pautam-se por sua origem profissional (se atuantes na formação inicial, científica e pedagógica) e ainda por sua inserção social, opções ideológicas e educativas. Desse modo, tais concepções não são estáticas: elas modificam-se ao longo do exercício da função docente.

Em referência específica ao professor de Matemática, Garnica e Fernandes (2002) afirmam que as concepções de um docente sobre a Matemática, seu ensino e aprendizagem resultam de um amalgamado de outros significados atribuídos por ele a essa ciência, construídos em sua formação, determinantes da e determinados por sua ação em sala de aula. As narrativas de nossos entrevistados nos possibilitaram perceber a pertinência das considerações desses autores.

Portanto, durante a formação de professores de Matemática na instituição que pesquisamos, nos anos 1960 a 1990, evidencia-se uma cultura acadêmica tecida sob a "certeza" de que o melhor estava sendo feito para uma formação inicial de qualidade. Para aqueles formadores, a possibilidade de reprodução das práticas ali engendradas, bem como o cultivo dos elementos daquela cultura acadêmica concorriam, sem dúvida, para a constituição de um bom professor e de sua prática para ensinar a Matemática.

\section{Referências}

Almeida, S. P. N. C. (2015) Um lugar: muitas histórias - o processo de formação de professores de matemática na primeira instituição de ensino superior da região de Montes Claros/Norte de Minas Gerais (1960-1990). Tese de Doutorado em Educação. Belo Horizonte: Universidade Federal de Minas Gerais.

Anastasiou, L. das G. C. (2004). Ensinar, aprender, apreender e processos de ensinagem. In: Anastasiou, L. das G. C., \& Alves, L. P. Processos de ensinagem na universidade: pressupostos para as estratégias de trabalho em aula. Joinville, SC: UNIVILLE.

Baraldi, I. M. (2003). Retraços da Educação Matemática na Região de Bauru (SP): uma história em construção. Tese de Doutorado em Educação Matemática. Rio Claro: Universidade Estadual Paulista. Retirada em 15 de junho, 2015, de: https://repositorio.unesp.br/handle/11449/102158

Bordignon, T. F. (2011). A Aliança para o Progresso e a educação como pretexto para a consolidação do capitalismo. Anais do XXVI Simpósio Nacional de História (pp. 1-9). São Paulo: Associação Nacional de História (ANPUH). Retirado em 10 de dezembro, 2018, de: 
DOI: https://doi.org/10.20396/zet.v27i0.8654227

http://www.snh2011.anpuh.org/resources/anais/14/1300881299_ARQUIVO_AAliancapa raoProgressoeaeducacaocomopretextoparaaconsolidacaodocapitalismo.pdf

Cunha, M. I. da. (1992). O bom professor e sua prática. São Paulo: Papirus.

Cury, H. (1994) As concepções de Matemática dos professores e suas formas de considerar erros dos alunos. Tese de Doutorado em Educação. Porto Alegre: Universidade Federal do Rio Grande do Sul. Retirada em 15 de junho, 2015, de: https://www.ime.usp.br/ brolezzi/teses.htm

Faria Filho, L. M. de., Gonçalves, I. A., Vidal, D. G., \& Paulilo, A. L. (2004). A cultura escolar como categoria de análise e como campo de investigação na história da educação brasileira. Educação e Pesquisa, 30(1), 139-159.

Fernandes, D. N. (2011). Sobre a formação do professor de Matemática no Maranhão: cartas para uma cartografia possível. Tese de Doutorado em Educação Matemática. Rio Claro: Instituto de Geociências e Ciências Exatas, Universidade Estadual Paulista. Retirada em 15 de junho, 2015, de: https://repositorio.unesp.br/handle/11449/102104?localeattribute $=\mathrm{es}$

Forquin, J. C. (1993). Escola e cultura: as bases sociais e epistemológicas do conhecimento escolar. Porto Alegre/RS: Artes Médicas.

Garnica, A. V. M., \& Fernandes, D. N. (2002). Licenciaturas em Matemática: um estudo sobre as concepções vigentes. Bauru: UNESP.

Julia, D. (2001). A cultura escolar como objeto histórico. Revista Brasileira de História da Educação, 1(1), 9-44.

Libâneo, J. C. (1994). Didática. São Paulo: Cortez.

Luckesi, C. C. (2005). Filosofia da Educação. São Paulo: Cortez Editora.

Macena, M. M. M. (2013). Sobre formação e prática de professores de Matemática: estudo a partir de relatos de professores, década de 1960, João Pessoa (PB). Tese de Doutorado em Educação Matemática. Rio Claro: Instituto de Geociências e Ciências Exatas, Universidade Estadual Paulista. Retirada em 15 de junho, 2015, de: https://repositorio.unesp.br/handle/11449/102121

Martins, P. L. O. (1998). A Didática e as contradições da prática. Campinas, SP: Papirus.

Martins-Salandim, M. E. (2012). A interiorização dos cursos de Matemática no estado de São Paulo: um exame da década de 1960. Tese de Doutorado em Educação Matemática. Rio Claro: Universidade Estadual Paulista. Retirada em 15 de junho, 2015, de: https://repositorio.unesp.br/handle/11449/102107

Mota, D. (2006). Chega de subjetividade: entrevista de Beatriz Sarlo. Trópico, São Paulo, 29 abr. 2006. Seção História. Retirado em 21 de março, 2019, de: http://www.revistatropico.com.br/tropico/html/textos/2735,1.shl

Pina, F. (2008). Acordo MEC-USAID: ações e reações (1966-1968). Anais do XIX Encontro Regional de História: Poder, Violência e Exclusão (pp.1-10). São Paulo: ANPUH/SPUSP. Retirado em 10 de dezembro, 2018, de: https://www.anpuhsp.org.br/sp/downloads/CD\%20XIX/PDF/Autores\%20e\%20Artigos/F abiana\%20Pina.pdf 
DOI: https://doi.org/10.20396/zet.v27i0.8654227

Ponte, J. P. da. (1992). Concepções dos professores de Matemática e Processos de Formação. Revista Educação Matemática: Temas de Investigação (pp.185-239). Disponível em: $<$ http://www.educ.fc.ul.pt/docentes/jponte/DOCS-PT/92-ponte(Ericeira).doc.

Saviani, D. (2003). Escola e democracia: teorias da educação, curvatura da vara, onze teses sobre a educação política. Campinas, SP: Autores Associados.

Silva, T. T. da. (2014). Documentos de identidade: uma introdução às teorias do currículo. Belo Horizonte: Autêntica.

Viñao Frago, A. (1995). Historia de la educación e historia cultural: Posibilidades, problemas, cuestiones. Revista Brasileira de Educação, (0), 63-82. Disponível em: http://anped.tempsite.ws/novo_portal/rbe/rbedigital/RBDE0/RBDE0_06_ANTONIO\%20 VINAO_FRAGO.pdf

\section{Fontes orais}

Durães, Rosa Terezinha Paixão. [2012]. Entrevistadora/transcritora: Shirley Patrícia Nogueira de Castro e Almeida. Montes Claros, 28 nov. 2012.

Ferreira, Ronaldo Dias. [2013]. Entrevistadora/transcritora: Shirley Patrícia Nogueira de Castro e Almeida. Montes Claros, 20 mai. 2013.

Gil, Francisco Bastos. [2013]. Entrevistadora/transcritora: Shirley Patrícia Nogueira de Castro e Almeida. Montes Claros, 03 jul. 2013.

Guimarães, Edson. [2013]. Entrevistadora/transcritora: Shirley Patrícia Nogueira de Castro e Almeida. Montes Claros, 28 mai. 2013.

Guimarães, Mariza Monteiro. [2013]. Entrevistadora/transcritora: Shirley Patrícia Nogueira de Castro e Almeida. Montes Claros, 28 mai. 2013.

Mourão, Dilma Silveira. [2012]. Entrevistadora/transcritora: Shirley Patrícia Nogueira de Castro e Almeida. Montes Claros, 03 dez. 2012.

Paixão, Maria de Lourdes Ribeiro. [2013]. Entrevistadora/transcritora: Shirley Patrícia Nogueira de Castro e Almeida. Montes Claros, 23 mai. 2013.

Ribeiro, Rosina Rabelo Nuzzi. [2013]. Entrevistadora/transcritora: Shirley Patrícia Nogueira de Castro e Almeida. Montes Claros, 04 jun. 2013.

Santos, Edson Crisóstomo dos. [2013]. Entrevistadora/transcritora: Shirley Patrícia Nogueira de Castro e Almeida. Montes Claros, 13 jun. 2013.

Souza, João Barbosa de. [2013]. Entrevistadora/transcritora: Shirley Patrícia Nogueira de Castro e Almeida. Montes Claros, 28 mai. 2013.

Souza, Sebastião Alves de. [2013]. Entrevistadora/transcritora: Shirley Patrícia Nogueira de Castro e Almeida. Montes Claros, 21 mai. 2013. 